\title{
Multi-objective attendance and management information system using computer application in industry strip
}

\author{
Ahmed Hazim Alhilali, Nabeel Salih Ali, Mohammed Falih Kadhim, Basheer Al-Sadawi, \\ Haider Alsharqi \\ Information Technology Research and Development Centre/University of Kufa, Iraq
}

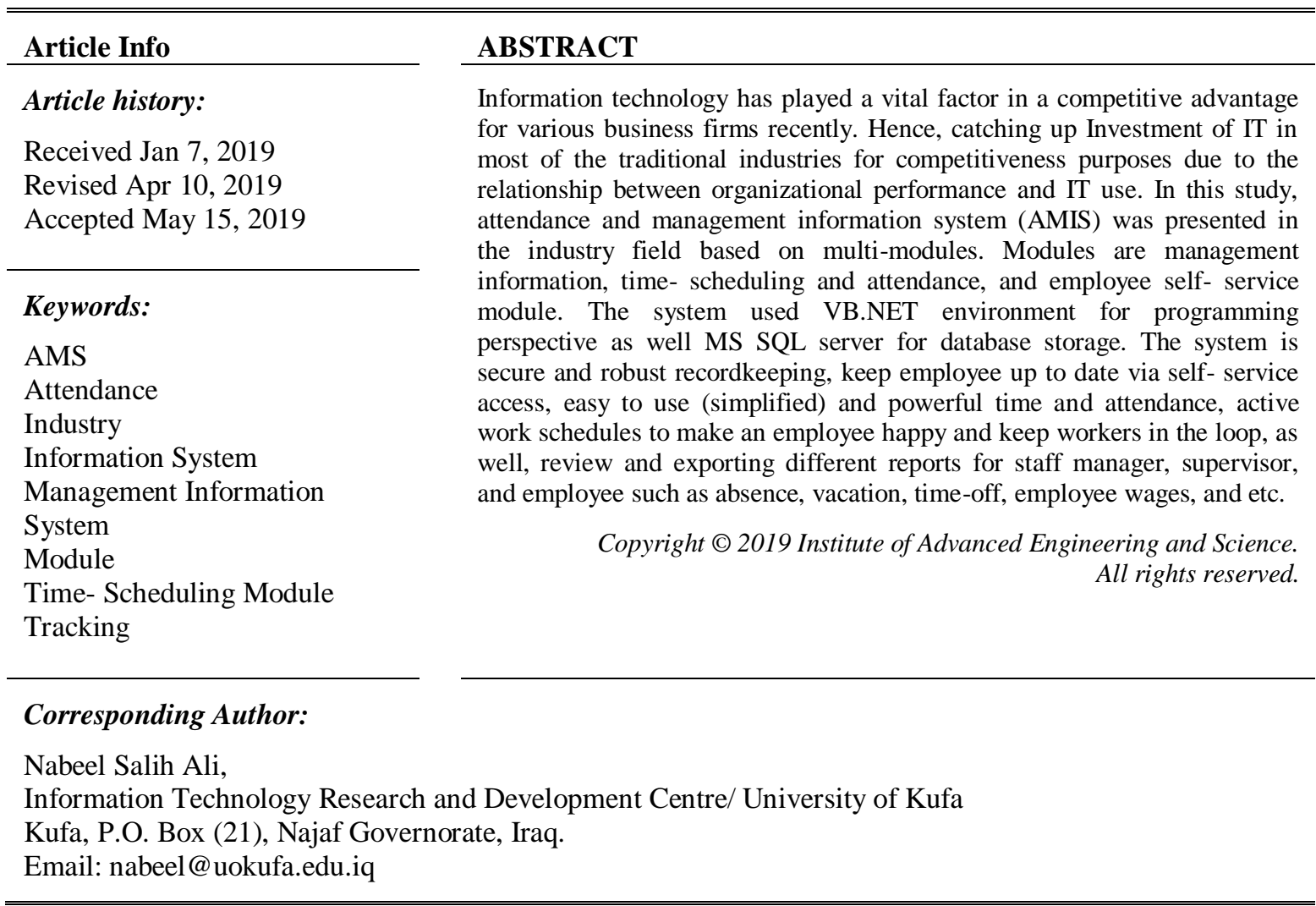

\section{INTRODUCTION}

Investment of information technology (IT) has become a significant source of competitive advantage in several firms, and they have not fully achieved benefits of IT use [1-3]. There is a relationship between organizational performanc, and IT use and it has been studied and investigated in general business literature [4-6]. Most of the traditional industries, small and medium scale companies, have changed their manual systems to digital due to it need too much time, human resources effort, and requires a long process $[7,8]$. Also, competitiveness would be in risk when companies are not catching up with the change [9, 10]. The employee management application is a powerful tool to relieve the user from the complicated task of handling employee scheduling manually [11]. Whereas employees have considered as the backbone of any corporation and the success of an organization is based on managing of the employee performance; Managing of human resources in a complex environment like the retail industry is a challenging task $[12,13]$. Hence information of the employees must be kept safe and secure as well the information should be done securely $[14,15]$. So, an effective information system (IS) in an organization should be managed in a trusted medium [13]. Whereas, several issues and problems affected the IS such as information security lacks and could be attractive to hacker attacks via injection of computer viruses [16, 17]. An attacker can access illegal and could destroy or damage the information in the system [18-21]. Therefore, this security issue factor can be considered as a negative impact on the effectiveness of an IS in a company [22]. Attendance records play a significant role in measuring the effectiveness, performance, and objectives 
achievement of an organization [23]. Hence, Absenteeism is a serious problem and an expensive occurrence for both employers and employees seemingly unpredictable due to it reflect the individual presentation [24]. Jayawardana in 2008 developed a timesheet software package to track and report employee attendance [25]. While, in 2010, Saraswat and Kumar proposed an automatic attendance system based on fingerprint image technique. The presented method was efficient, effective, accurate, and faster execution [26]. According to Fairchild (2012), proposed an automated time and attendance processes in industry sector [27]. As well, Bhuiyan (2013) examines the use and combination of the human resources and information system (HRIS) in both the manufacturing and service sectors [28]. Azani et al., 2015 conducted a low-cost Facebook status monitoring system for individual attendance status. The proposed system using status messages in social media [29]. Kumar et al., 2016, GPS and GPRS technologies are introduced to monitor, track and registered a people in institutions or organizations. The person should be wearied ID card to be monitored. MEMS GPS and GPRS are integrated with ARM microcontroller [30]. Soewito et al., 2016 presented a system that can be recorded employees attendance concerning outside the building as well accounting salary that included overtime easily. Fingerprint and voice recognition biometrics technology with a smartphone is used. The false positive of verification fingerprint is (95\%) while, voice recognition false negative is (5.88\%) [31]. Nguyen et al., 2017, the authors developed an automated attendance system to record, track and management attendance registration records. The system used RFID with mobile wireless communication. The mechanism provides collecting, recording and processing data on participants on professional gatherings [32]. Liang et al., 2017 an integrated electronic attendance system applied city government and its subordinate organizations. The designed electronic system integrated for several business characteristics such as reliability, practicality, and possess integrity [33]. Besides, a research is provided a mechanism for smart attendance management along with timetable, student information system providing a wide database for university students and staff members [34].

In this article, employees' attendance and management information system for both industrial and organizational sectors is proposed. Three modules are conducted to achieve the research objectives which include attendance module, management information and tracing module, and time- scheduling module. The rest of the article sections are presented as follow consecutively. Section 2 sheds light on the system methodology that it contains multi-module to achieve its objectives. Whereas, Section 3 involves the proposed AMIS implementation and their results. Discussion the results was in Section 4 respectively. Finally, conclusions and further studies will be explained in Section 5.

\section{METHODOLOGY OF PROPOSED ATTENDANCE AND MANAGEMENT INFORMATION SYSTEM (AMIS)}

The methodology of the proposed system includes three modules. These modules are management information, time-scheduling and attendance, and employee self-service module. Figure 1 presents overall function modules of the proposed system.

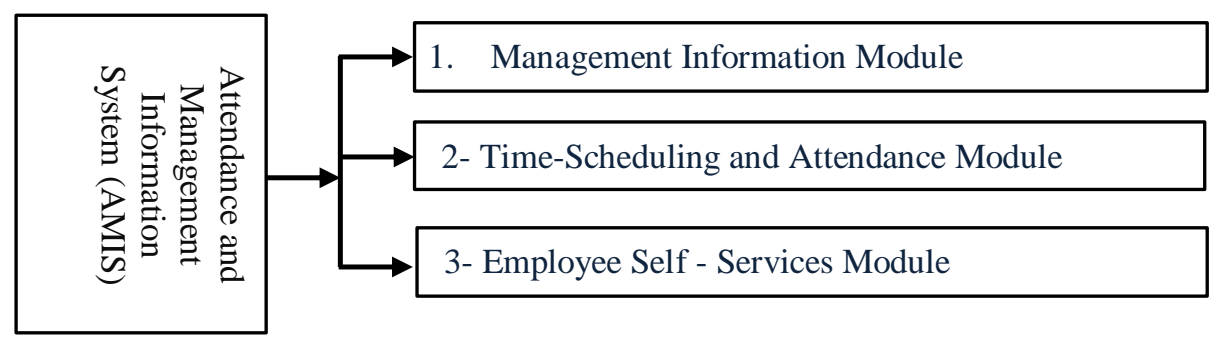

Figure 1. Overall system function modules

\subsection{Management information module}

Figure 2 shown multi-phase of the management information modules. The first phase which is regarding users' rules and privileges of the system administration. Three users are involved in the system which encompasses admin, user, and employee. While the second phase is an industry section structure that responds to conduct the structure of the industry sections and work schedules. However, the next phase respect to employee end that performs multifunction such as employee registration records maintenance, and smart tracking for an employee. Backup and restore data, as well as generating reports are the final phase in the first module of the presented system. 


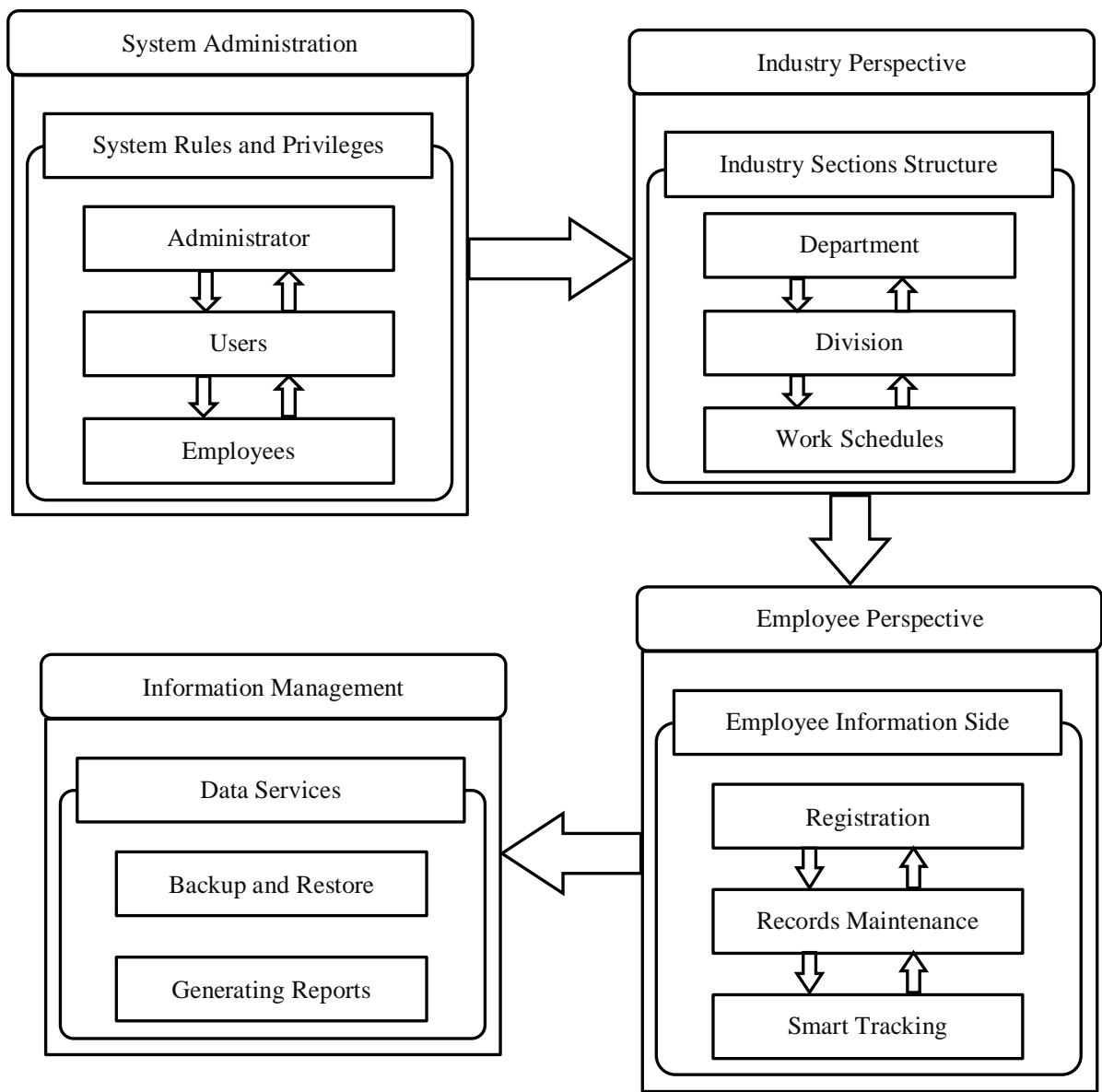

Figure 2. Four-phases of the management information module

\subsection{Time-scheduling and attendance module}

Attendance systems have been rated as one of the critical elements or issues that reflects the domain achievements and the performance contributed to such organization, industry, enterprise, and university compared to the traditional methods that impose time-consuming and inefficiency [35]. Due to support, sustain and increase their businesses and performance. The attendance system can be used to analyze human resources, control day-to-day attendance, monitor the leave and absence records and transfer the overtime information to the payroll system [36, 37]. It enables these organizations to keep track of attendance, assessment their employees and make it is a critical standard that allows measuring the organizations' efficiency [38-40]. Figure 3 presents the function structure of the time- scheduling and attendance module.

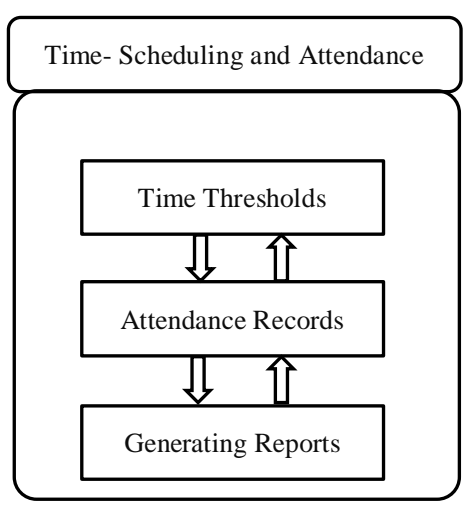

Figure 3. The function Structure of the time-scheduling and attendance module

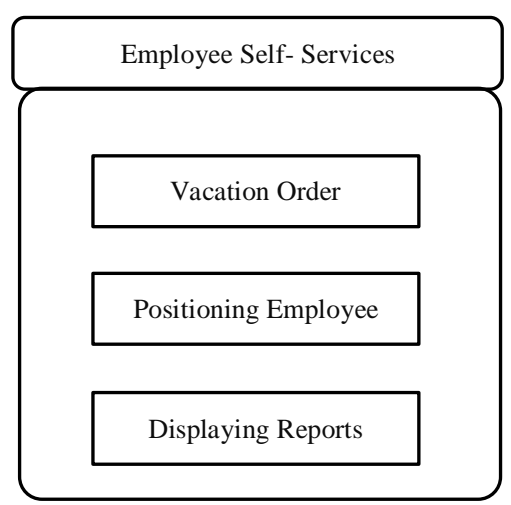

Figure 4. Multi-function of the employee self-service module 


\subsection{Employee self- service module}

The proposed system provides several employee self- services features to easily allowing employees to review their schedules easily, sending vacation order, sending change work schedules or time-shifting set the "where am I" via an employee to tacking employee, and easily show regardless reports easily. As we can see in Figure 4 which listed the employee self-service module.

\section{IMPLEMENTATION AND RESULTS}

\subsection{Database system design and structure}

The database used to conduct several functions in the proposed system regarding an industry data and employees information. MS SQL server is used in VB.NET environment with C\# language. Figure 5 display all database tables of the proposed system. To illustrate all the tables in the database and describe their functions. Figure 6 presents the system dashboard.

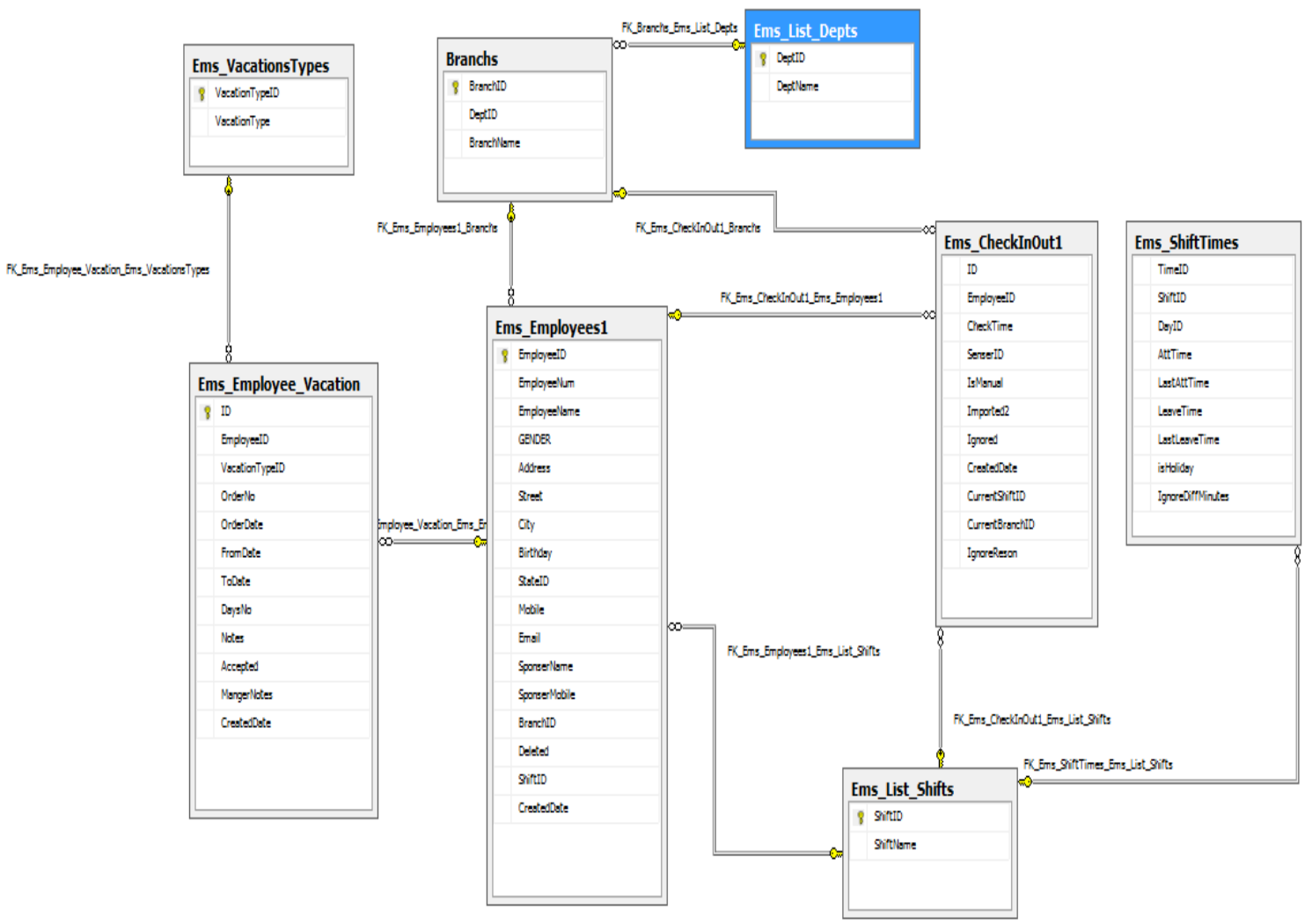

Figure 5. Attendance and management information system relations

\section{The company name}
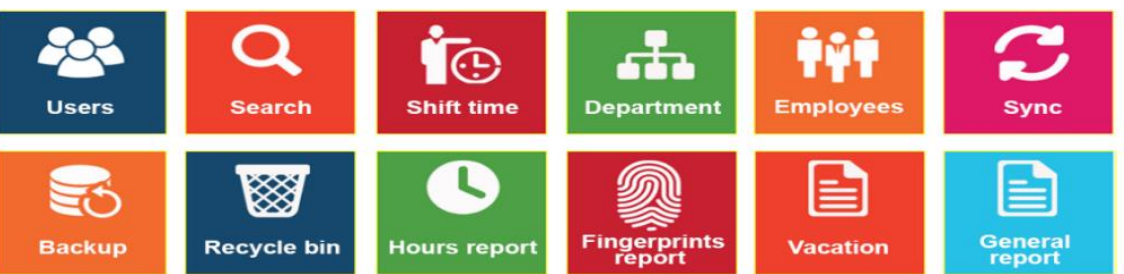

Figure 6. Dashboard of proposed system 


\subsection{Management information module}

\subsubsection{System administration with users privileges and rules (phase one)}

Admins, users, and employees can be logged and surf the proposed system with different permission via the login form. The permission of the administrator is having full accessing to the system database, adding, deleting and editing the user or even the reports, while the user (worker) has minimum permissions related to the database. Whilst an employee has few permissions in the system that allowing them access to the database and displayed related reports and sending orders. Table 1 presents all rules and permission for both admin, user, and employee.

Table 1. System administrations with different user's permissions and system management

\begin{tabular}{|c|c|c|c|}
\hline Rules & Admin & User & Employee \\
\hline Register Employee & & & $\bar{x}$ \\
\hline Create and edit industry sections & & & $x$ \\
\hline Edit and add attachments to an employee & & & $x$ \\
\hline Manage work schedules for employees & & & $x$ \\
\hline Set times thresholds for work schedules & & & $x$ \\
\hline Searching for an employee & & & $x$ \\
\hline Display and print report & & & $x$ \\
\hline Present deleted records & & & $x$ \\
\hline Receive requests from an employee & & & $x$ \\
\hline Sending notifications for employees & & & $x$ \\
\hline Backup and Restore Data & & & $x$ \\
\hline Sending request for vacations & & & $\checkmark$ \\
\hline Display working times for a particular employee & & & $\checkmark$ \\
\hline Receive notifications & & & $\checkmark$ \\
\hline Setting the value of the Field "where am I" & & & $\checkmark$ \\
\hline
\end{tabular}

\subsubsection{Industry sections structure (phase two)}

The AMIS provides an ability to structure industry sections, branches or divisions. Figure 7 presents the GUI implemented to an industry sections structure. The department button enables a particular admin to add a new department or sections and edit or delete the existing one.

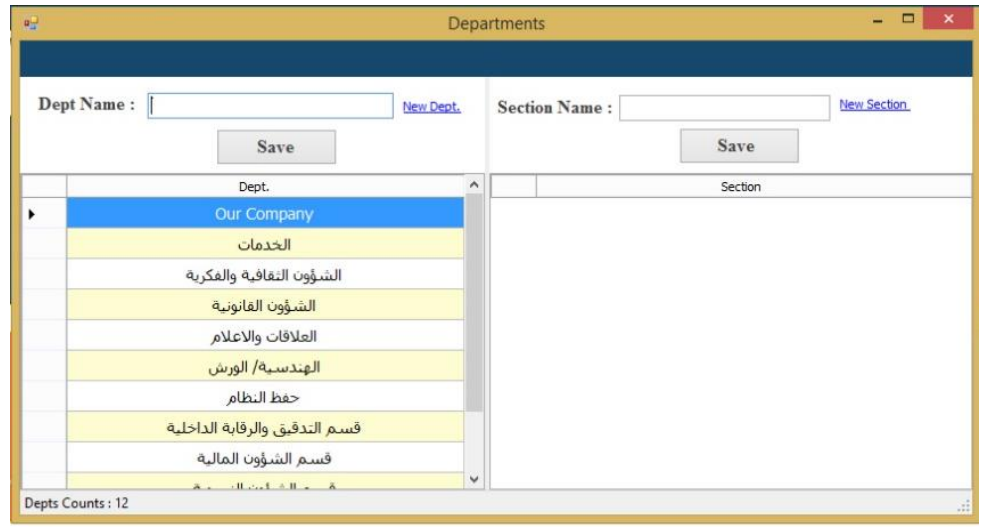

Figure 7. Structure of industry sections

\subsubsection{Employee management information (phase three)}

Managing employee information by an application has been considered a powerful tool to reduce user task complexity from scheduling manually. Registration, record maintenance, and smart tracking of an employee are important to the success of any corporation or organization in a complex environment. Due to, employees have considered as the backbone of any industry is and managing of human resources is a challenging task. Figure 8 presents the registration and maintenance employee's records respectively. 


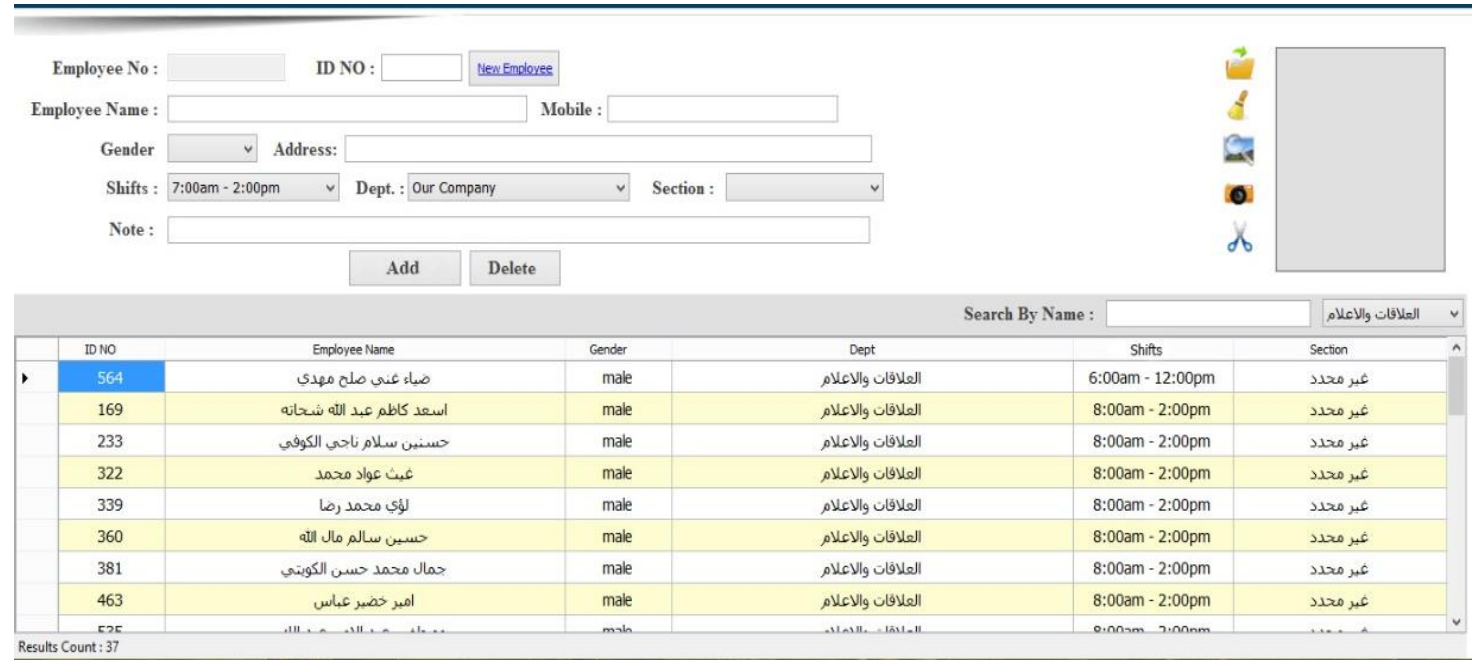

Figure 8. Present the implementation of registration and maintenance employee records

User registration process starts with a click on the employee button and then entering the information of the users, which includes personal one such as ID number, full name, gender, users working shift. Moreover, the system enables adding a photo for the employee and notes. However, all information that added can be edited and maintained later. Also, system admins can search for an employee by name, card number, and department and section helshe works. The process ended by storing all the data into the MS SQL database.

Hence, analyzing the human resources daily and control the employee's attendance, and monitoring leave and absence records is a crucial issue in measuring the organizations' efficiency. Tracking an employee attendance, monitoring leaving and absence of human resources is a vital trend to assess their employees. The system provides a smart tracking employee by analyzing the suitable work schedule for a particular employee based on their assessment results.

\subsubsection{Backup and restore data (phase four)}

Supporting restoring and backup of the data is a significant aspect to make sure keep the data availability and prevent damaged or corrupted it due to illegal access via a crafter or destroy the system if any. As well as, the proposed system provides generating reports that need human resources. Figure 9 displays the function of backup and restore data as well as generating reports consecutively.

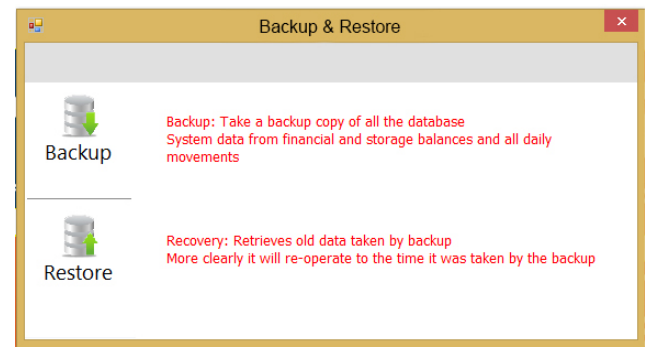

Figure 9. Backup and restoring the data and reports generating

\subsection{Time-scheduling and attendance module}

The system store all employee data securely. Data like personal information, job and supervisor details, and more. Also, the system provides adding employees one at a time or import them all at once. Also, the system supports detail report regarding information for both absences and pull a time-off for each employee. The system Create and save recurring work schedules for multi- using for several purposes. Work schedules or staff schedules has been a complex task and selecting and generating schedules based on 
employee availability and filtered by job skills. Hence, it can be calculated employee wage and overtimes quickly and easily. Figure 10 shows the implementation of time-schedules with time- thresholds. The Shift Time button allows the admin to add and manage the working shifts. All new shift need the following inputs to be entered which are: shift name, working days, attend time, threshold, time to leave, last time to leave and ignore. Table 2 explains each input. To create a new working shift, the system admin starts with naming the shift and assign it to work for all weekdays or some. After that, other shift setting such as attend time, threshold, time to leave, Last time to leave, and ignore must be configured.

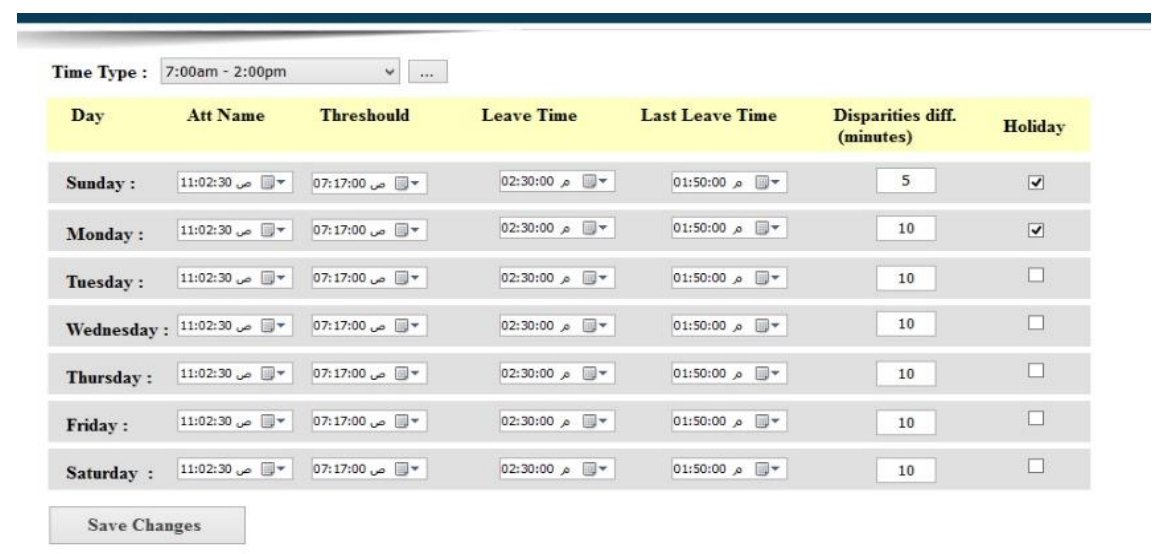

Figure 10. System implementation of time-schedules and time-thresholds

Table 2. Multi-button inputs and their functions

\begin{tabular}{cc}
\hline Shift name & Unique name represent the shift \\
Working days & In which day/s this shift will work? \\
Attend time & The employees attendance time \\
Threshold & limit on a scale \\
Time to leave & The employees leaving time \\
Last time to leave & Max time accepted in the system after time to leave \\
Ignore & This input is active when the employee vacation or there is a national holiday
\end{tabular}

The system can generate four types of reports regarding staff and employees attendance ratios. First, General Report that shows employees names, the department they work for, identity number, date, attendance time, leave time, a status which includes (present, absent, late, early departure, departure, on vacation), and notes. Furthermore, the result of the General Report can be filtered depending on the working shift time and period. Second, Fingerprint Report which shows the following details for each employee (id number, employee name, fingerprint time). This type of report can give a result for a specific date. Third, Vacation Leave Report displays information about employees on vacation that include (employee name, date from, date to, date back to work, note), it also can be filtered for a specific duration. Finally, Hours Report that enables the system admin to get the exact number of working hours for each employee. The report shows the following information (employee name, department, id number, date, attendance time, leave time, working shift, working minutes, and working hours). Moreover, date duration is available for this type of report. Figure 11 presents the ability to generating reports regarding searching for an employee based on different criteria.

\subsection{Employee self-services module}

Employee Self-Service has been providing save time due to it letting your staff do more on their own. These services include make time-off requests and submit timesheets without bothering their supervisors and staff manager. When an employee submits a request for vacation days or other time off, and etc. Supervisors can use the system to review and approve employee requests that it received by notification and prevent understaffing and conflicts based on seeing who else is out before approving a request. Displaying the time-off report upcoming and previous time off for any employee during any period and printed it as a report to make sure the industry has an effective work schedule. Figure 12 display submit a request for a vacation by an employee. 
As well, the proposed system provides another feature in employee self-service that setting the positioning of an employee via service "Where Am I" to easier connect with other employees in a variety of ways. Also, the ability to send a text message directly to an employee to communicate even faster. In addition to, the proposed scheduling software allows employees to review their schedules easily by the desktop application and inquiries about shift changes to time-off requests systematically.

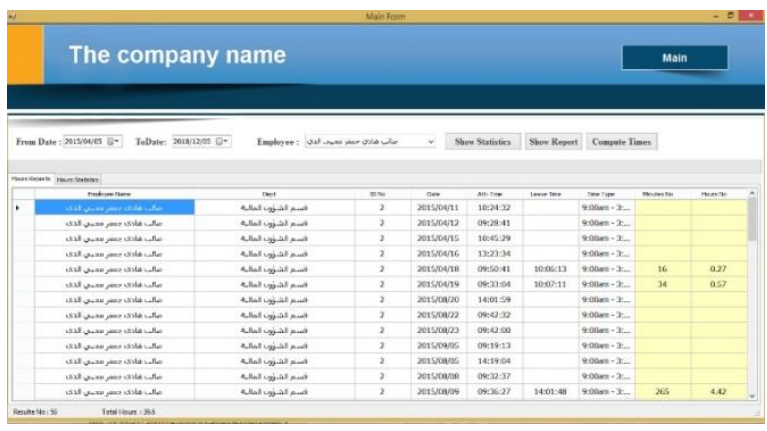

(a) Vacation report

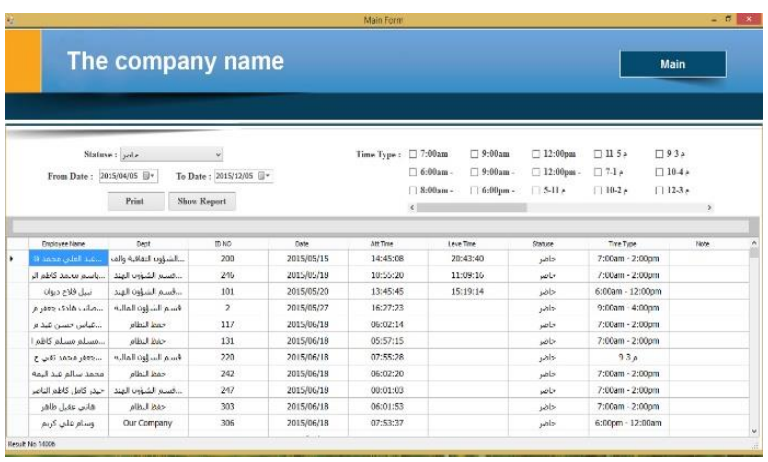

(c) General report

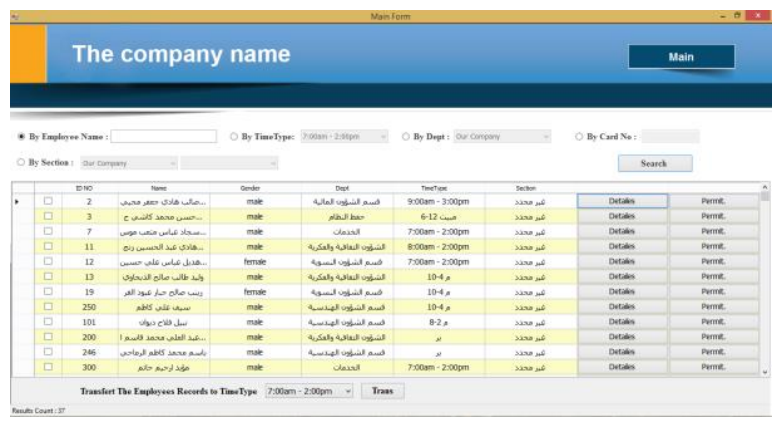

(b) Hours report

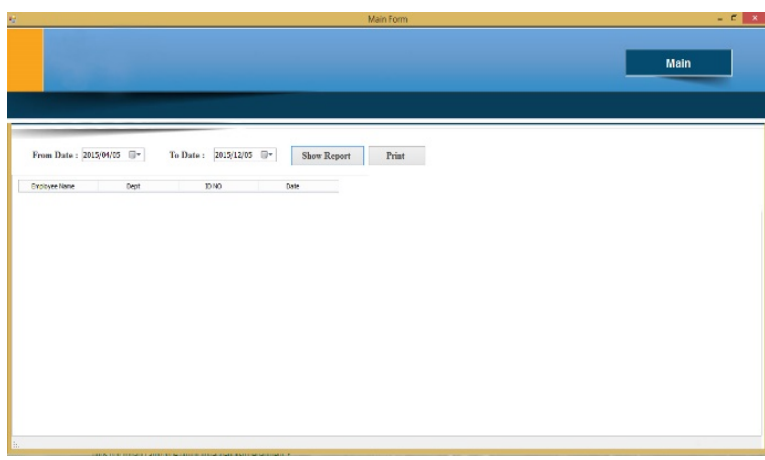

(d) Fingerprints report

Figure 11. Generating report for employee respect to several conditions

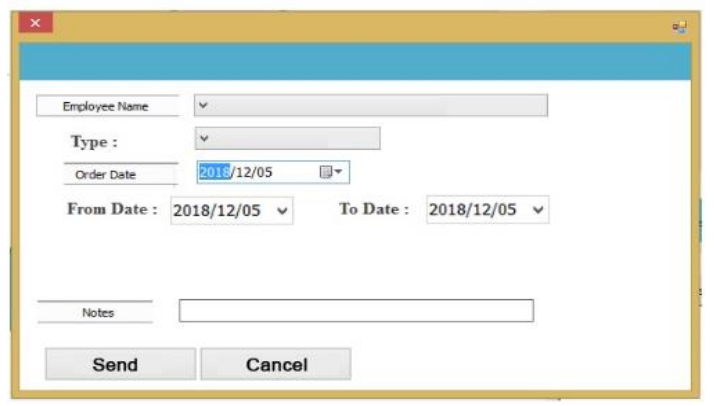

Figure 12. Sending Request for Vacation in Employee Self-Service

\section{RESULTS DISCUSSION}

Based on the previous section (see Section 3) which implemented and tested the proposed attendance and management information system for an industry sector based on a computer-based system. The system has multi-objective modules such as time-scheduling and attendance, management information, and employee self- service module (see Section 2). Scheduling the employee's time based on employee availability and filtered by job skills to save time, efficient ways to manage employee wages, create regular schedules daily, weekly, or monthly. And finally effective work schedules. Whereas, the system provides 
simplified and easy to use employees time and attendance with a powerful software tool (see Section 3.3). The software tool introduces a secure and robust recordkeeping that it includes simplifying attendance tracking, store employees' data in a central location, and store all information in trust and a secure manner (see Section 3.2). The system can register, edit, and delete an employee, structure industry sections, maintenance employee records, and smart tracking tool. Instead of submitting paper forms, several employee requests can be sent like vacation days, time-off days, work schedules changes, and etc by employee selfservice (see Section 3.4). Self- service will make an employee happy due to the employee can swap shifts easily and quickly, keep the employee in the system loop to allow them to show their schedules, requests, upcoming shifts in easily and friendly manner. As well, self- service provide feature "Where Am I" to position the employee location work to allow supervisors, other employees easily tracking, communicate with other employees. Displaying and generating reports that include absence detail reports, time- off summary report, and employee hour reports for any period easily and quickly (see Sections 3.2, 3.3, and 3.4). Table 3 described all the system features and functions. Table 4 provides an overview of the system objectives.

Table 3. The proposed system functions

\begin{tabular}{|c|c|}
\hline System Desktop Application-Based Function & Notes \\
\hline \multicolumn{2}{|l|}{ Dashboard View } \\
\hline Detailed Employee Recordkeeping & Security By MSSQL Server \\
\hline \multirow[t]{2}{*}{ Intelligent Reporting } & 4-7 intelligent Reports but the report "Customizable "Favorite" \\
\hline & Reports Save You Time" not found \\
\hline Robust \& Secure Recordkeeping: & $\begin{array}{l}\text { To ensure from the security of MSSQL server } \\
\text { https://docs.microsoft.com/en- }\end{array}$ \\
\hline a. Simplify Attendance Tracking & us/dotnet/framework/data/adonet/sql/overview-of-sql-server-security \\
\hline \multirow{3}{*}{\multicolumn{2}{|c|}{$\begin{array}{l}\text { b. Store Employee Profiles in a Central Location } \\
\text { c. Saved for When You Need Them } \\
\text { d. Save the Date }\end{array}$}} \\
\hline & \\
\hline & \\
\hline \multirow{2}{*}{\multicolumn{2}{|c|}{$\begin{array}{l}\text { Make Shift Schedules in Just One Click } \\
\text { Comply with Overtime Laws }\end{array}$}} \\
\hline & \\
\hline Efficient Ways to Manage Employee Wages & Given the Cost of Hour for each Shift or employee in each Day \\
\hline \multicolumn{2}{|l|}{ Create Work Schedules in Seconds } \\
\hline \multicolumn{2}{|l|}{ Set It and Forget It Shift Creation } \\
\hline \multicolumn{2}{|l|}{ Employee Hour Reports for Any Period } \\
\hline \multicolumn{2}{|l|}{ View Time-Off and Vacation Requests } \\
\hline \multicolumn{2}{|l|}{ Easy Shift Swapping } \\
\hline Effective Work Schedules & \\
\hline
\end{tabular}

\section{CONCLUSIONS AND FUTURE STUDIES}

The current study introduced an attendance and management information system (AIMS) for the industry sector. The proposed system includes three modules which are management information, timescheduling and attendance, and employee self- service module to achieve system functions. The system used MS SQL server in VB.NET environment with C\# language to create and design the database end. After implement and tested the system in an industry, the system was capable of robust and secure the detailed employee recordkeeping, tracking of employee schedules, exports absences and time-off reports, making the employee happy via employee self- service and keeping them with the system loop via providing "Where Am I" feature. In the future perspective, conduct a web-based application that includes several functions such as review all reports by employees and managers, provides chat among employees to communicate easily with each other. As well as, extend the system to include mobile- based application with multi- features like sending alerts to employee via mobile for shift times, auto detect location mechanism based on the geographic location "where Am I" depend on the Access Point mobile connection, additionally, monitoring and tracking employees by GPS with industry mapping.

\section{REFERENCES}

[1] Clegg, C., Axtell, C., Damodaran, L., Farbey, B., Hull, R., Lloyd-Jones, R., ... \& Tomlinson, C. (1997). Information technology: a study of performance and the role of human and organizational factors. Ergonomics, 40(9), 851-871.

[2] Kang, Y., O'Brien, W. J., \& Mulva, S. P. (2013). Value of IT: Indirect impact of IT on construction project performance via Best Practices. Automation in Construction, 35, 383-396. 
[3] Ali, N. S., Alyasseri, Z. A. A., \& Abdulmohson, A. (2018). Real-Time Heart Pulse Monitoring Technique Using Wireless Sensor Network and Mobile Application. International Journal of Electrical and Computer Engineering, $8(6)$.

[4] Strassmann, P. A. (1990). The business value of computers: an executive's guide. Information Economics Press.

[5] Strassmann, P. A. (1997). The squandered computer: evaluating the business alignment of information technologies. Strassmann, Inc..

[6] Hitt, L. M., \& Brynjolfsson, E. (1996). Productivity, business profitability, and consumer surplus: three different measures of information technology value. MIS quarterly, 121-142.

[7] Patrol Management System Applying RFID to Petrochemical Industry.

[8] Al-Khammasi, S., Alhelal, D., \& Ali, N. S. (2018). Energy Efficient Cluster Based Routing Protocol for Dynamic and Static Nodes in Wireless Sensor Network. TELKOMNIKA (Telecommunication Computing Electronics and Control), 16(5), 1974-1981.

[9] Development of Generic Automated Employee Daily Time Record Management System Using RFID

[10] [Alathari, B., Kadhim, M.F., Al-Khammasi, S., Ali, N.S. (2019). A Framework Implementation of Surveillance Tracking System Based on PIR Motion Sensors. Indonesian Journal of Electrical Engineering and Computer Science, 13(1), pp. 235-242.

[11] Employee Management Application within an Organization Using Android Smartphone's

[12] Rana, M. \& Hossain, N. 2014. Human Resource Management (HRM) practices of the banking sector in Bangladesh: a comparative study. Banglavision, 14(1):18-27.

[13] Kadhim H. A., Ali, N. S., Dheyaa M. Abdulsahib (2019). Management and Achieving System for Metal Detection Robot Using Wireless-Based Technology and Online Database Registry. International Journal of Power Electronics and Drive System, 10(1), pp. 219- 229.

[14] Ngaochay, T. \& Walsh, J. 2015. Human resource development activities in a retail franchise in Thailand: the case of coffee world. Journal of Economics and Behavioral Studies, 7(1):72- 78.

[15] Arora, K. 2013. Importance of HRIS: a critical study on service sector. Global Journal of Management and Business Studies, 3(9):971-976.

[16] Davarpanah, A. \& Mohamed, N. 2013. Human Resource Information Systems (HRIS) success factors in a public higher education institution context. In 3rd International Conference on Research and Innovation in Information Systems (ICRIIS'13), Malaysia: 79- 84.

[17] Zafar, H. 2013. Human Resource Information Systems: information security concerns for organizations. Human Resource Management Review, 23(1):105-113.

[18] Ali, N.S. (2018) 'Investigation framework of web applications vulnerabilities, attacks and protection techniques in structured query language injection attacks', Int. J. Wireless and Mobile Computing, Vol. 14, No. 2, pp.103-122.

[19] Mohite, B.J. 2012. Impact of managing personnel records in an electronic environment (HRIS) on business organizations and related problems. In Ninth AIMS International Conference on Management, Pune, India: 645651.

[20] Halfond, W.G.J., Viegas, J. and Orso, A. (2006, March) 'A classification of SQL-injection attacks and countermeasures', Proceedings of the IEEE International Symposium on Secure Software Engineering, Vol. 1, pp.13-15.

[21] Ali, N.S. (2016) 'A four-phase methodology for protecting web applications using an effective real-time technique', Int. J. Internet Technology and Secured Transactions, Vol. 6, No. 4, pp.303-323.

[22] The Impact Of Human Resources Information Systems In Selected Retail Outlets In Western Cape

[23] A Study on Symptoms and Preventions of Employee Absenteeism

[24] Absence management and presenteeism: the pressures on employees to attend work and the impact of attendance on performance.

[25] Timesheet: An Attendance Tracking System

[26] An Efficient Automatic Attendance System using Fingerprint Verification Technique

[27] Fairchild, Micah. "The Top Reasons Every Company Needs Time/Attendance Software." Retrieved August 17, 2014 from http://www.hrlab.com/time-attendance- software.php.

[28] Bhuiyan, M.R.U. 2013. Application of Human Resource Information System in the firms of Bangladesh and its strategic importance. Proceedings. Annual Paris Business and Social Science Research Conference, France: 1-10.

[29] Developing Information System of Attendance and Facebook Status for Binus University's Lecturer Usi ng Raspberry Pi Architecture

[30] Nagothu, S. K., \& Anitha, G. (2016). GPS Aided Autonomous Monitoring and Attendance System. Procedia Computer Science, 87, 99-104.

[31] Soewito, B., Gaol, F. L., Simanjuntak, E., \& Gunawan, F. E. (2016, July). Smart mobile attendance system using voice recognition and fingerprint on smartphone. In Intelligent Technology and Its Applications (ISITIA), 2016 International Seminar on (pp. 175-180). IEEE.

[32] Nguyen, H. K., \& Chew, M. T. (2017, February). RFID-based attendance management system. In Recent Trends in Telecommunications Research (RTTR), Workshop on (pp. 1-6). IEEE.

[33] Liang, X. Q., Li, W. Y., \& Lu, T. C. (2017, August). A Study of the Multi-Organization Integrated Electronic Attendance System. In International Conference on Intelligent Information Hiding and Multimedia Signal Processing (pp. 53-61). Springer, Cham. 
[34] Rjeib, H. D., Ali, N. S., Al Farawn, A., Al-Sadawi, B., \& Alsharqi, H. (2018). Attendance and Information System using RFID and Web-Based Application for Academic Sector. International Journal of Advanced Computer Science and Applications (IJACSA), 9(1). http://dx.doi.org/10.14569/IJACSA.2018.090137.

[35] Arif, Z. H., Ali, N. S., Zakaria, N. A., \& Al-Mhiqani, M. N. (2018). Attendance Management System for Educational Sector: Critical Review. International Journal of Computer Science and Mobile Computing, 7(8), August- 2018, pp. 60-66.

[36] Jacob, J., Jha, K., Kotak, P., \& Puthran, S. (2015, October). Mobile attendance using Near Field Communication and One-Time Password. In Green Computing and Internet of Things (ICGCIoT), 2015 International Conference on (pp. 1298-1303). IEEE.

[37] Shakil, M., \& Nandi, R. N. (2013). Attendance Management System for Industrial Worker using Finger Print Scanner. Global Journal of Computer Science and Technology.

[38] Sayanekar, P., Rajiwate, A., Qazi, L., \& Kulkarni, A. (2016). Customized NFC enabled ID card for Attendance and Transaction using Face Recognition. International Research Journal of Engineering and Technology, 3(9), pp. 1366- 1368.

[39] Noor, S. A. M., Zaini, N., Latip, M. F. A., \& Hamzah, N. (2015, December). Android-based attendance management system. In Systems, Process and Control (ICSPC), 2015 IEEE Conference on (pp. 118-122). IEEE.

[40] Shoewu, O., \& Idowu, O. A. (2012). Development of attendance management system using biometrics. The Pacific Journal of Science and Technology, 13(1), 300-307. 